\title{
Lipopolysaccharide and $\beta$-1,3-glucan binding protein in the hard clam (Meretrix meretrix): Molecular characterization and expression analysis
}

\author{
S.X. Liu' ${ }^{1}$, Z.H. Qi' ${ }^{2}$, J.J. Zhang', C.B. He ${ }^{3}$, X.G. Gao ${ }^{3}$ and H.J. Li $^{1}$
}

${ }^{1}$ Key Laboratory for Ecological Environment in Coastal Areas, State Oceanic Administration, National Marine Environmental Monitoring Center, Dalian, China

${ }^{2}$ South China Sea Fisheries Research Institute, Chinese Academy of Fishery Sciences, Guangzhou, China

${ }^{3}$ Key Laboratory of Marine Fishery Molecular Biology of Liaoning Province, Liaoning Ocean and Fisheries Science Research Institute, Dalian, China

Corresponding author: $\mathrm{H}$. Li

E-mail: hjli@nmemc.gov.cn

Genet. Mol. Res. 13 (3): 4956-4966 (2014)

Received May 28, 2013

Accepted January 10, 2014

Published July 4, 2014

DOI http://dx.doi.org/10.4238/2014.July.4.10

ABSTRACT. Pattern recognition molecules play an important role
in innate immunity by recognizing conserved molecular patterns
that are present on the surface of invading microorganisms. In
this study, a lipopolysaccharide and $\beta$-1,3-glucan binding protein
$(L G B P)$ gene was cloned from the hard clam Meretrix meretrix
(designated as $M m-L G B P$ ) by the expressed sequence tags and rapid
amplification of cDNA ends method. The cDNA was $1827 \mathrm{bp}$ in
length, consisting of a 71 -bp 5'-terminal untranslated region, a $62-$
bp 3'UTR, and a $1734-\mathrm{bp}$ open reading frame encoding a 577 -amino
acid polypeptide with an estimated molecular mass of $60.7 \mathrm{kDa}$
and a theoretical isoelectric point of 5.56 . Characteristic potential 
polysaccharide binding, cell adhesion, and glucanase motifs were identified in the $M m-L G B P$, indicating that $M m-L G B P$ should be a new member of the $L G B P$ family. Quantitative real-time polymerase chain reaction was developed to detect the mRNA expression level of $M m-L G B P$ in 6 different tissues. Higher-level mRNA expression of $M m-L G B P$ was detected in the gill and digestive gland tissues. The upregulation of $M m-L G B P$ mRNA after Vibrio anguillarum challenge showed that $M m-L G B P$ play a pivotal role in antibacterial immunity.

Key words: Meretrix meretrix; Hard clam; Gene cloning; Lipopolysaccharide and $\beta$-1,3-glucan binding protein; mRNA expression

\section{INTRODUCTION}

The recognition of an invading organism as foreign is the first critical step in any immune response. Unlike vertebrates, invertebrates lack an adaptive immune system, and they rely on innate immune responses against invading organisms (Janeway Jr. and Medzhitov, 2002). Invertebrates possess the ability to recognize conserved pathogen-associated molecular patterns (PAMPs), such as $\beta$-1,3-glucan (BG), lipopolysaccharide (LPS), and peptidoglycan (PG), which are present on the surface of bacteria and fungi (Medzhitov and Janeway Jr., 2002). Pattern recognition molecules act as biosensors in the activation of innate immune responses in both vertebrates and invertebrates (Fabrick et al., 2003). Recently, several pattern recognition proteins (PRPs) have been isolated and characterized, including $\mathrm{BG}$ recognition protein (BGRP), LPS-binding protein (LBP), PG-binding protein (PGBP), LPS- and BG-binding protein (LGBP), Gram-negative bacteria-binding protein (GNBP), thioester-containing protein, C-type lectin, galactoside-binding lectin (galectin), and fibrinogen-like domain immunolectin (Dziarski, 2004). It has been demonstrated that common motifs, such as bacterial glucanase-like (Kim et al., 2000; Ochiai and Ashida, 2000), bacteriophage lysozyme-like (Yoshida et al., 1996), and immunoglobulin-like (Fearon and Locksley, 1996) motif, exist in part of their primary structure.

Several PRPs have been cloned and characterized in aquatic animals, such as the crayfish Pacifastacus leniusculus LGBP (Lee et al., 2000), kuruma shrimp Marsupenaeus japonicas LGBP (Lin et al., 2008), Chinese shrimp Fenneropenaeus chinensis LGBP (Liu et al., 2009), Zhikong scallop Chlamys farreri LGBP (Su et al., 2004), disk abalone Haliotis discus BGRP (Nikapitiya et al., 2008), and pearl oyster Pinctada fucata LGBP (Zhang et al., 2010). It was demonstrated that Pacifastacus leniusculus LGBP played an important role in prophenoloxidase (proPO) activation (Lee et al., 2000). The proPO activating system is an important non-self-recognition system in invertebrates that can be activated by LPS or peptidoglycan from bacteria and $\beta$-1-3-glucans from fungi (Hoffmann et al., 1996). The active form of proPO, known as phenoloxidase (PO), can melanize pathogens, sclerotize the cuticle, and heal wounds in invertebrates (Wang et al., 2007).

The hard clam (Meretrix meretrix) is a bivalve mollusk of the family Veneridae that is native to the south-north coastal area of China. It is an important aquaculture species in China 
and fetches a high price in the Internet trade market. However, over the past decades, the clam aquaculture industry has experienced serious disease and high mortality (Yue et al., 2010). Understanding the immune response mechanisms would be beneficial for disease control in clam aquaculture. To date, many immune-related genes have been cloned and their expression profiles analyzed in the hard clam (Yang et al., 2011; Yue et al., 2011a,b; Li et al., 2012; Gao et al., 2012). However, to our knowledge, there is no information about gene characterization or gene expression of hard clam PRPs. Therefore, to further understand the function of bivalve PRPs in the innate immune response, it is necessary to clone and characterize more PRP genes in the hard clam.

\section{MATERIAL AND METHODS}

\section{Clam collection}

Adult M. meretrix (2 years old, shell length 4.5-5.5 cm) were collected from Guanhe Aquaculture Corporation in Panjin (Bohai Sea, China). Clams were cultured in sand-filtered seawater at $18^{\circ}-20^{\circ} \mathrm{C}$ for 10 days before the challenge experiments. The seawater was aerated continuously, and the salinity was set at $28 \%$. Clams were fed Chlorella vulgaris (10 $\mathrm{mg}$ dry mass $\cdot$ clam $^{-1} \cdot$ day $^{-1}$ ) during the acclimatization period. To investigate the tissue-specific expression pattern of $M m-L G B P, 6$ tissues including hemocytes, mantle, gill, adductor muscle, digestive gland, and gonad, were collected from 5 unchallenged clams. Hemolymph was collected from adductor muscles using a sterile syringe and then centrifuged at $1000 \mathrm{~g}$ for $10 \mathrm{~min}$ at $4^{\circ} \mathrm{C}$. All samples were stored in liquid nitrogen until RNA extraction.

\section{Bacterial challenge}

Two hundred clams were used for the bacterial challenge experiment. Clams that were immersed in a high density of Vibrio anguillarum with final concentration of $10^{9} \mathrm{CFU} / \mathrm{mL}$ were used as the challenge group. The untreated clams were used as the control group. Each group was divided into 3 replicates. Hemocytes and gill were sampled at 2, 4, 6, 8, 16, and 32 $\mathrm{h}$ post challenge. Three individuals of each replicate were randomly sampled at the same time point and were pooled together as 1 sample.

\section{RNA extraction and cDNA synthesis for gene cloning}

Total RNA was extracted using Trizol reagent (Invitrogen, USA) according to the manufacturer protocol. Total RNA was incubated with RNase-free DNase I (Roche, USA) to remove any genomic DNA. First-strand cDNA was synthesized from $2 \mu \mathrm{g}$ total RNA by MMLV reverse transcriptase using oligo $\mathrm{d}(\mathrm{T})_{15}$ (Takara, China) at $37^{\circ} \mathrm{C}$ for $60 \mathrm{~min}$.

\section{Cloning and sequencing the full-length cDNA of Mm-LGBP}

Random sequencing of SMART cDNA libraries generated 3224 successful sequencing reactions (Li et al., 2011). Basic local alignment search tool (BLAST) (National Center for Biotechnology Information, NCBI) analysis of all obtained sequences revealed that an 
expressed sequence tag (EST) of 689 bp was homologous to previously identified LGBPs. This EST sequence, Mm-LGBP, was selected for cloning and further investigation. One genespecific primer, Mm-LGBP-3' (Table 1), was designed to amplify the full-length cDNA of $M m-L G B P$ using the rapid amplification of cDNA ends (RACE) approach. Polymerase chain reaction (PCR) amplification of the $3^{\prime}$ end of $M m-L G B P$ was carried out with Mm-LGBP-3' and T7 primers (Table 1). The PCR conditions were as follows: $94^{\circ} \mathrm{C}$ for $5 \mathrm{~min} ; 35$ cycles of $94^{\circ} \mathrm{C}$ for $30 \mathrm{~s}, 55^{\circ} \mathrm{C}$ for $30 \mathrm{~s}$, and $72^{\circ} \mathrm{C}$ for $1 \mathrm{~min}$; and an additional extension of $72^{\circ} \mathrm{C}$ for $10 \mathrm{~min}$. The PCR product was cloned into the pMD18-T vector (Takara) and sequenced in both directions.

\begin{tabular}{lll}
\multicolumn{2}{l}{ Table 1. Primers used in this study. } & \\
\hline Primer name & Sequence (5'-3') & Primer information \\
\hline Mm-LGBP-3' & CTTTGAACGATGGTCCAGATAGC & 3'RACE primer \\
T7 & GTAATACGACTCACTATAGGGC & Vector primer \\
LGBP -RTF & ATGAACGTGGCTGTCGAG & Real-time LGBP primer \\
LGBP -RTR & ACGTAGGATACCACTGACCACG & Real-time $\beta$-actin primer \\
Actin-RTF & GATCATTGCCCACCAGAGAG & \\
Actin-RTR & CCAGACTCGTCGTATTCTTGTTTAC & \\
\hline
\end{tabular}

\section{Sequence alignment and phylogenetic tree}

The $M m-L G B P$ sequence was analyzed using the BLAST algorithm at the NCBI website (http://www.ncbi.nlm.nih.gov/blast). The amino acid sequence was predicted using the Expert Protein Analysis System (http://www.expasy.org/). The molecular mass and theoretical isoelectric point calculated were predicated by the EMBOSS model of protein isoelectric point program (http://isoelectric.ovh.org/). Multiple protein sequence alignments of $M m-L G B P$ with proteins from other species were performed using the ClustalW program (http://www.ebi. ac.uk/clustalw/). A phylogenetic tree was constructed according to the amino acid sequences of HSPs selected using the neighbor-joining (NJ) method in the MEGA 4.0 program (Tamura et al., 2007). The bootstrap trials were replicated 1000 times to derive the confidence values for the phylogeny analysis.

\section{Analysis of Mm-LGBP mRNA expression using quantitative real-time (qRT)-PCR}

The mRNA expression of $M m-L G B P$ in different tissues of healthy clams was measured by qRT-PCR. The gene-specific primers LGBP-RTF and LGBP-RTR (Table 1) were designed to amplify the target gene. A pair of primers for clam $\beta$-actin (Actin-RTF and ActinRTR, Table 1) was used to amplify $\beta$-actin as an internal control. Reactions were performed in a total volume of $25 \mu \mathrm{L}: 12.5 \mu \mathrm{L} 2 \mathrm{X}$ SYBR Premix Ex Taq ${ }^{\mathrm{TM}}, 0.5 \mu \mathrm{L}$ ROX II, $1.0 \mu \mathrm{L}$ each primer $(10 \mu \mathrm{M}), 2.0 \mu \mathrm{L}$ diluted $\mathrm{cDNA}$, and $8.0 \mu \mathrm{L}$ diethylpyrocarbonate water. The thermal profile was set as follows: $95^{\circ} \mathrm{C}$ for $30 \mathrm{~s}$, followed by 40 cycles of $95^{\circ} \mathrm{C}$ for $5 \mathrm{~s}$ and $60^{\circ} \mathrm{C}$ for $50 \mathrm{~s}$. Dissociation curve analysis was performed at the end of each reaction to confirm that only 1 PCR product was amplified and detected. The $2^{-\Delta \Delta C t}$ method (Livak and Schmittgen, 2001) was used to analyze expression levels. All data were given in terms of relative mRNA expressed as the means \pm standard deviation (SD). The data were subjected to analysis by oneway analysis of variance (ANOVA), using SPSS 13.0. A P value $<0.05$ was considered to be statistically significant. 


\section{RESULTS AND DISCUSSION}

\section{cDNA cloning and sequence analysis of Mm-LGBP}

A 970-bp fragment was amplified by 3'RACE, sequenced, and overlapped with an EST sequence to generate the full-length cDNA sequence of $M m-L G B P$. The sequence was deposited in GenBank under accession No. KC958578. The complete sequence of $M m-L G B P$ cDNA consisted of a 71-bp 5'-terminal untranslated region (5'-UTR), a 62-bp 3'-UTR with a poly (A) tail, and a 1734-bp open reading frame (ORF) encoding a polypeptide of 577 amino acids with an estimated molecular mass of $60.7 \mathrm{kDa}$ and a theoretical isoelectric point of 5.56. SMART analysis revealed that the amino acid region from 215 to 550 belonged to the glycoside hydrolase family 16 . The Mm-LGBP amino acid sequence contained a potential recognition motif for the $\beta$-1,3-linkage of polysaccharides, a putative cell adhesion site, a glucanase motif, and a protein kinase C phosphorylation site (Figure 1). An LPS-binding site was also found in the Mm-LGBP sequence (Figure 1). Moreover, 2 putative N-glycosylation sites were identified at positions $\mathrm{N}_{138} \mathrm{QT}_{140}$ and $\mathrm{N}_{249} \mathrm{RT}_{251}$ (Figure 1).

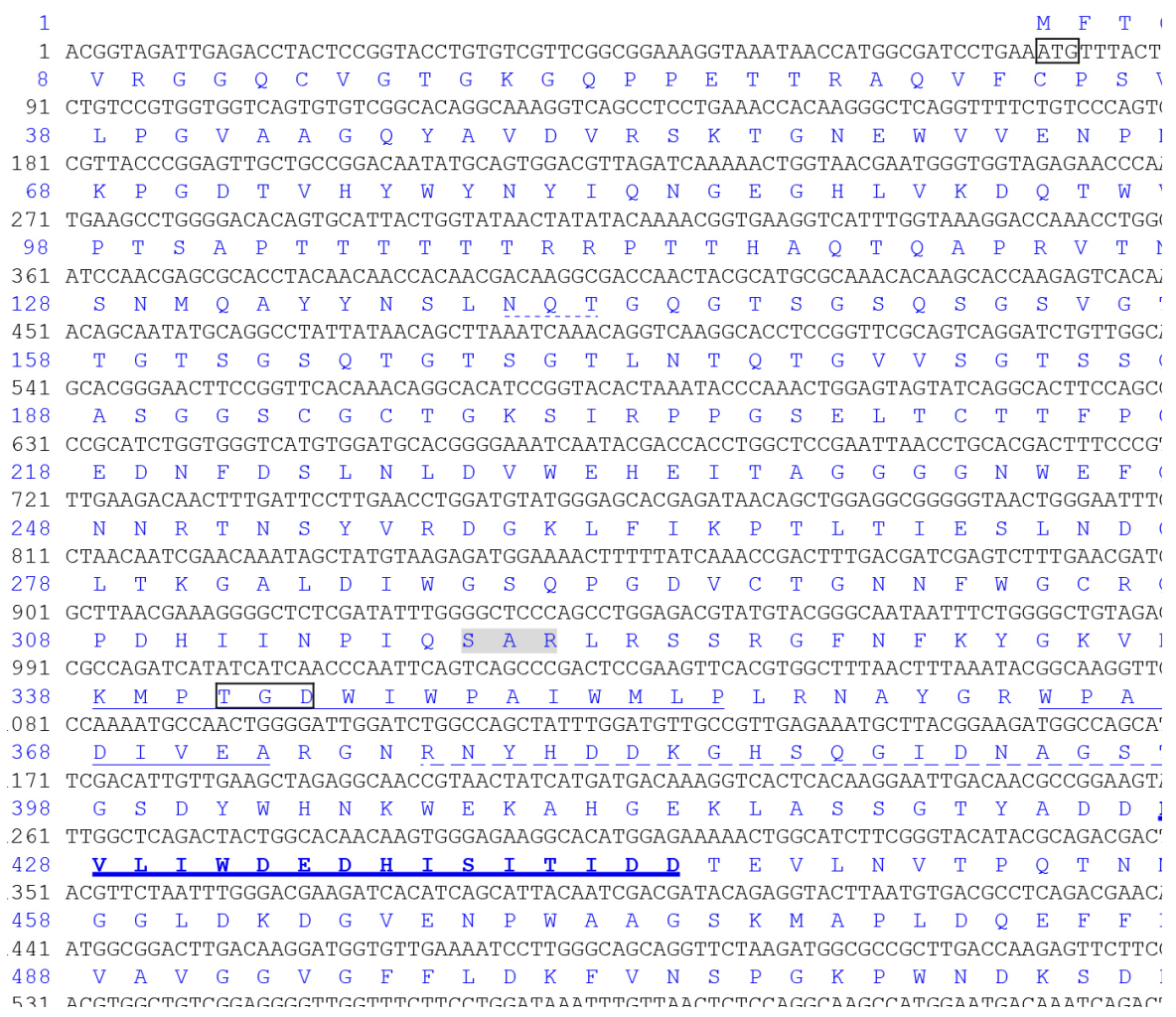

Figure 1. Nucleotide and deduced amino acid sequences of Mm-LGBP. The start codon (ATG) and stop codon are boxed (TAG). A potential recognition motif for $\beta$-1,3-linkage of polysaccharides is bold and underlined. A protein kinase $\mathrm{C}$ phosphorylation site is shaded and a putative cell adhesive site is boxed. The putative glucanase and polysaccharide binding (PsB) motifs are underlined. Two putative N-glycosylation sites were dotted and underlined. The LPS binding motif is dashed and underlined. 


\section{Alignment and phylogenetic tree of Mm-LGBP}

Multiple sequence alignment of Mm-LGBP with other known molluscan LGBP and LGBP amino acid sequences revealed the strong conservation in the polysaccharide binding (PsB) and glucanase motifs (Figure 2) despite the species-to-species variation in the length of the amino acid sequence. The Mm-LGBP amino acid sequence shared significant homology with other known invertebrate PRPs (Table 2). It had the highest identity (77\%) to Tapes literatus BGRP, and shared $64-25 \%$ similarity with other PRP sequences. Using the NJ method, a phylogenetic tree was constructed based on the amino acid sequences of selected invertebrate PRP sequences (Figure 3). Insect BGRPs were grouped into 1 cluster, crustacean BGRP and LGBP were grouped into 1 cluster, and insect GNBP were grouped into 1 cluster. Mm-LGBP was grouped into the PRPs that were identified from other mollusk species, such as clam Tapes literatus BGRP, snail Biomphalaria glabrata BGRP, Zhikong scallop Chlamys farreri LGBP, pearl oyster Pinctada fucata LGBP, Pacific oyster Crassostrea gigas BGRP, and disk abalone Haliotis discus BGRP. It is noteworthy that mollusk B. glabrata GNBP was not positioned within the same mollusk clade and was grouped with annelids coelomic cytolytic factor-like sequences.

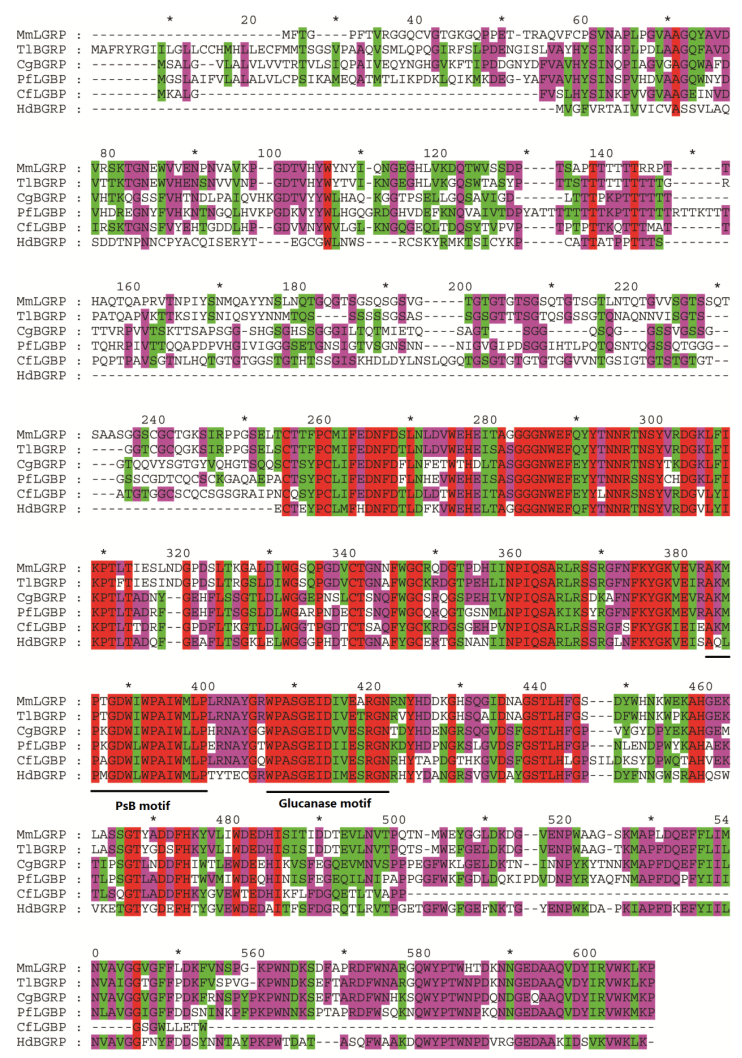

Figure 2. Multiple sequence alignments of Mm-BGRP with other known molluscan BGRPs and LGBPs. The red shading indicates identical amino acids, and the pink and green shading indicates conservative replacements. Putative polysaccharide binding (PsB) and glucanase motifs are underlined. The numbers above the sequence indicate the amino acid position in the corresponding amino acid species. 
S.X. Liu et al.

Table 2. Homology analysis of Mm-BGRP amino acid sequence with other known PRP amino acid sequences.

\begin{tabular}{|c|c|c|c|c|}
\hline Species & GenBank No. & Abbreviation-type & Amino acid size (aa) & Similarity $(\%)$ \\
\hline Meretrix meretrix & KC958578 & Mm-LGRP & & \\
\hline Tapes literata & AEE89455 & Tl-BGRP & 571 & 77 \\
\hline Biomphalaria glabrata & ABL63380 & Bg-BGRP & 393 & 64 \\
\hline Biomphalaria glabrata & ABO40828 & Bg-GNBP & 435 & 34 \\
\hline Haliotis discus & $\mathrm{ABO} 26613$ & Hd-BGRP & 420 & 50 \\
\hline Crassostrea gigas & BAG82629 & Cg-BGRP & 555 & 52 \\
\hline Chlamys farreri & AAP82240 & Cf-LGBP & 440 & 52 \\
\hline Pinctada fucata & ACN76701 & Pf-LGBP & 585 & 49 \\
\hline Fenneropenaeus chinensis & AAX63902 & Fc-LGBP & 366 & 50 \\
\hline Litopenaeus vannamei & ABU92557 & Lv-LGBP & 367 & 51 \\
\hline Marsupenaeus japonicus & ABY89089 & Mj-LGBP & 354 & 49 \\
\hline Penaeus monodon & AAM21213 & Pm-BGRP & 366 & 52 \\
\hline Homarus gammarus & CAE47485 & Hg-BGRP & 367 & 49 \\
\hline Anopheles merus & ABU80009 & Am-GNBP & 395 & 44 \\
\hline Anopheles quadriannulatus & ABU80018 & Aq-GNBP & 395 & 44 \\
\hline Anopheles gambiae & ABU80037 & Ag-GNBP & 395 & 44 \\
\hline Aedes aegypti & EAT38985 & Aa-GNBP & 386 & 45 \\
\hline Culex quinquefasciatus & XP 001845963 & Cq-GNBP & 286 & 47 \\
\hline Aporrectodea rosea & AAY 85744 & Ar-CCF-like & 385 & 43 \\
\hline Lumbricus rubellus & AAY 85746 & Lr-CCF-like & 385 & 42 \\
\hline Dendrobaena veneta & AAY 85745 & Dv-CCF-like & 384 & 42 \\
\hline Bombyx mori & NP 001036840 & Bm-BGRP & 495 & 27 \\
\hline Galleria mellonella & CAK 22401 & Gm-BGRP & 490 & 28 \\
\hline Manduca sexta & AAN10151 & Ms-BGRP & 482 & 25 \\
\hline Plodia interpunctella & AAM95970 & Pi-BGRP & 488 & 26 \\
\hline
\end{tabular}

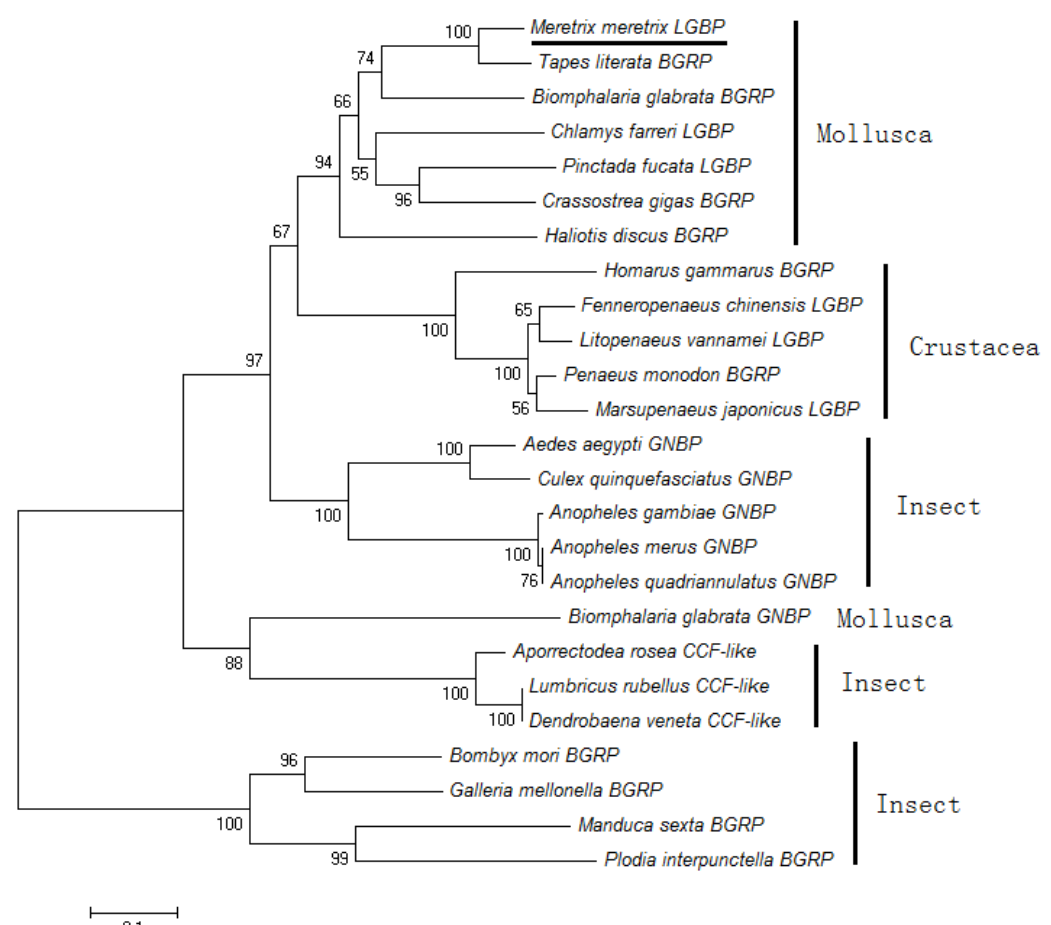

Figure 3. Consensus neighbor-joining tree based on the amino acid sequences of different types of pattern recognition proteins (PRPs). The numbers at the forks indicated the bootstrap. 


\section{Tissue distribution of Mm-LGBP mRNA}

The expression level of $M m-L G B P$ mRNA in 6 tissues tested was quantified by qRTPCR with $\beta$-actin as an internal control. For both $M m-L G B P$ and $\beta$-actin genes, there was only 1 peak at the corresponding melting temperature in the dissociation curve analysis, indicating that the PCR amplifications were specific. The tissue distribution of $M m-L G B P$ mRNA is shown in Figure 4. The $M m-L G B P$ transcript was broadly expressed in all tissues tested, with predominant detection in the gill, digestive gland, and mantle tissues, and less expression in the adductor muscle, gonad, and hemocytes tissues (Figure 4).

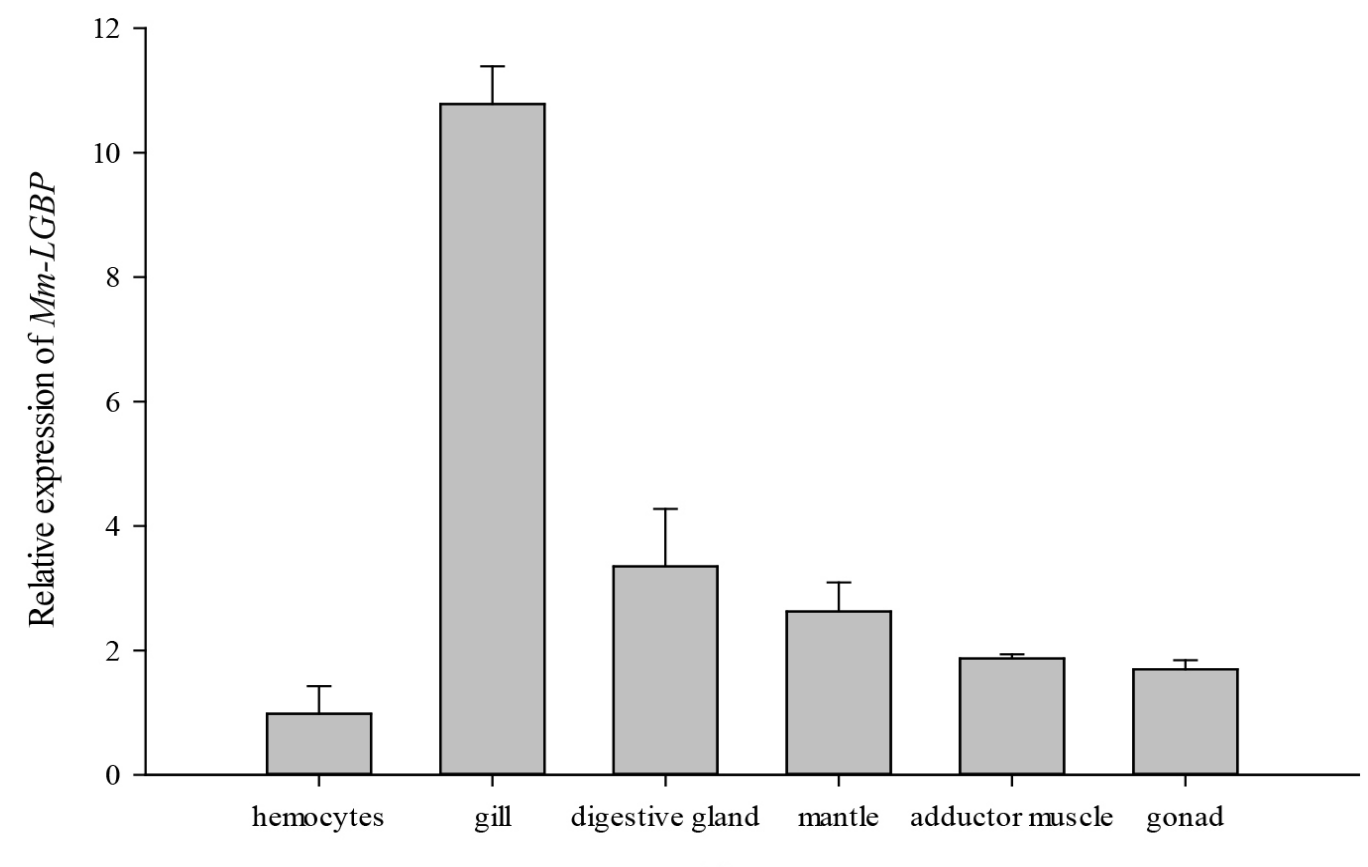

Tissues

Figure 4. Expression level of the $M m-L G B P$ mRNA in different tissues. Quantitative real-time RT-PCR was carried out with RNA samples from hemocytes, gill, digestive gland, mantle, adductor muscle and gonad of the adult tissues of hard clam. The hard clam $\beta$-actin gene was used as an internal control to calibrate the cDNA template for all the samples. Vertical bars represented the means $\pm \mathrm{SD}(\mathrm{N}=5)$.

Invertebrate PRPs have been demonstrated to be expressed in tissue-specific patterns. The kuruma shrimp $L G B P$ was expressed specifically in hemocyte tissue, but it was not detected in gills, hepatopancreas, muscle, eyestalk, and intestine (Lin et al., 2008). The fleshy prawn $L G B P$ was mainly expressed in hemocyte tissue, and very low levels of transcript also was detected in hepatopancreas and gills, but the transcript was not detected in heart, stomach, and intestine (Cheng et al., 2005). In this study, the $M m-L G B P$ mRNA was mainly expressed in the gill, which was similar to the BGRP expression profile in disk abalone (Nikapitiya et al., 2008). The gill, which is constructed of only a single layer of fragile cells and covered with a thin layer of protective mucus, has extensive contact with the environment. High expression of $M m-L G B P$ in gill suggests that the gill may be the first line of defense in hard clam because of its frequent exposure to the environment and to defend against invading foreign materials. 


\section{Temporal expression of Mm-LGBP after bacterial challenge}

The temporal expression of $M m-L G B P$ mRNA in gill and hemocytes after Vibrio anguillarum challenge was investigated by qRT-PCR (Figure 5). In the gill, the expression level of $M m-L G B P$ mRNA remained at a low level during the first $6 \mathrm{~h}$. At $2 \mathrm{~h}$, the level of $M m-L G B P$ transcript significantly decreased $(\mathrm{P}<0.05)$. However, $8 \mathrm{~h}$ after bacterial challenge, the $M m-L G B P$ mRNA level was significantly upregulated $(\mathrm{P}<0.01)$ and reached a peak that was 10.7 -fold higher than the level in the control. In hemocytes, at $6 \mathrm{~h}$ after bacterial challenge, the expression level of $M m-L G B P$ increased sharply to 3.2-fold higher than that in the control group. After $6 \mathrm{~h}$, the $\mathrm{Mm}$ $L G B P$ mRNA expression dropped gradually, and it returned to the original level at $16 \mathrm{~h}$.

A

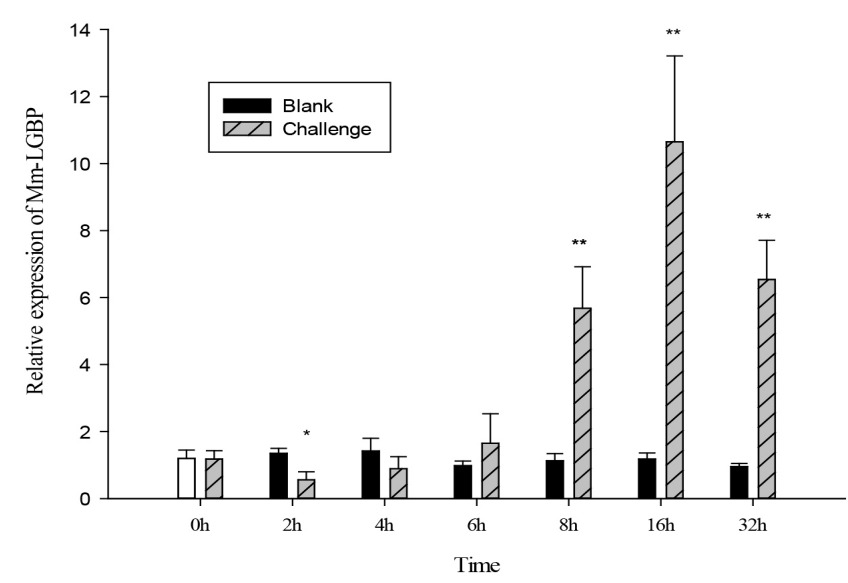

B

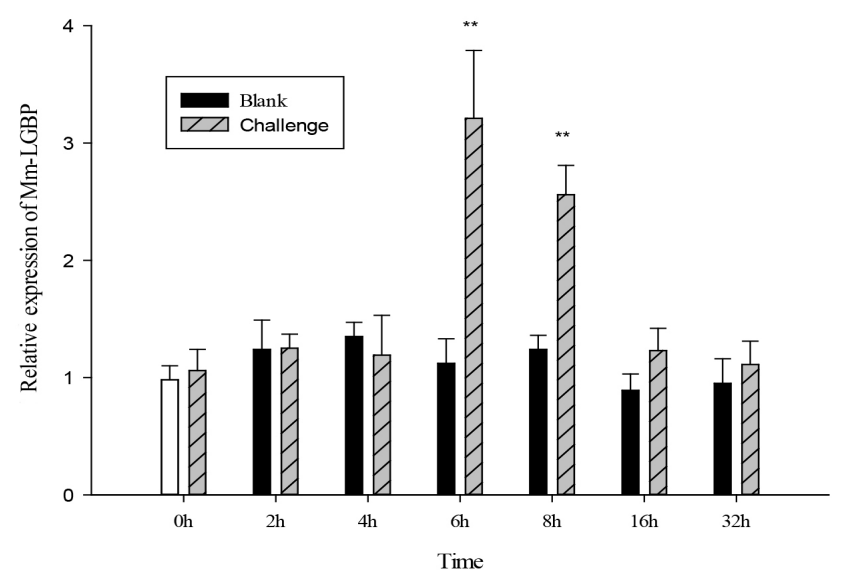

Figure 5. Temporal expression Mm-LGBP mRNA in gill (A) and hemocytes (B) after Vibrio anguillarum challenge measured by real-time PCR. The Mm-LGBP mRNA expression was normalized to blank group, and $\beta$-actin was used as an internal control to calibrate the cDNA template for all the samples. Each bar represents the mean value from three replicates with standard error. Three individuals sampled at the same time point were pooled together as one replicate. 
The temporal expression patterns of $M m-L G B P$ mRNA in gill and hemocytes after Vibrio anguillarum challenge was recorded to further investigate its possible biological function. The gill represents the main interface between aquatic organisms and the external environment. Bivalve mollusk gills are one of the first lines of defense against bacterial infection; it has become increasingly evident that the hemocytes play a central role in the internal defense of bivalves (Pipe, 1990; Bachere et al., 1991; Wang et al., 2012). The upregulation of $\mathrm{Mm}$ LGBP mRNA after Vibrio anguillarum challenge showed that Mm-LGBP plays a pivotal role in antibacterial immunity, further confirming the presence of the LPS recognition and binding site in Mm-LGBP. As the main structure component of outer membrane of most gram-negative bacteria and a potent stimulator of proinflammatory cytokines, LPS significantly upregulated the mRNA level of LGBPs in several marine invertebrates, including kuruma shrimp (Lin et al., 2008), crayfish (Lee et al., 2000), and disk abalone (Nikapitiya et al., 2008). The data in this study revealed that when a foreign object enters the body, the $M m-L G B P$ gene shows an increasingly higher level of transcription. This suggests that Mm-LGBP functions by recognizing different PAMPs and may activate different immune genes to defend against these pathogens.

\section{ACKNOWLEDGMENTS}

Research supported by the National Natural Science Foundation of China (\#31101899), a grant from the Zhejiang Key Laboratory of Exploitation and Preservation of Coastal BioResource (\#J2012001), and an open fund from the Key Laboratory of Fishery Ecology and Environment, Guangdong Province (\#GDKFL2012-06).

\section{REFERENCES}

Bachere E, Hervio D and Mialhe E (1991). Luminol-dependent chemiluminescence by hemocytes of two marine bivalves, Ostrea edulis and Crassostrea gigas. Dis. Aquat. Org. 11: 173-180.

Cheng W, Liu CH, Tsai CH and Chen JC (2005). Molecular cloning and characterisation of a pattern recognition molecule, lipopolysaccharide- and beta-1,3-glucan binding protein (LGBP) from the white shrimp Litopenaeus vannamei. Fish Shellfish Immunol. 18: 297-310.

Dziarski R (2004). Peptidoglycan recognition proteins (PGRPs). Mol. Immunol. 40: 877-886.

Fabrick JA, Baker JE and Kanost MR (2003). cDNA cloning, purification, properties, and function of a beta-1,3-glucan recognition protein from a pyralid moth, Plodia interpunctella. Insect Biochem. Mol. Biol. 33: 579-594.

Fearon DT and Locksley RM (1996). The instructive role of innate immunity in the acquired immune response. Science 272: $50-53$.

Gao X, He C, Liu H, Li H, et al. (2012). Intracellular Cu/Zn superoxide dismutase (Cu/Zn-SOD) from hard clam Meretrix meretrix: its cDNA cloning, mRNA expression and enzyme activity. Mol. Biol. Rep. 39: 10713-10722.

Hoffmann JA, Reichhart JM and Hetru C (1996). Innate immunity in higher insects. Curr. Opin. Immunol. 8: 8-13.

Janeway CA Jr and Medzhitov R (2002). Innate immune recognition. Annu. Rev. Immunol. 20: 197-216.

Kim YS, Ryu JH, Han SJ, Choi KH, et al. (2000). Gram-negative bacteria-binding protein, a pattern recognition receptor for lipopolysaccharide and beta-1,3-glucan that mediates the signaling for the induction of innate immune genes in Drosophila melanogaster cells. J. Biol. Chem. 275: 32721-32727.

Lee SY, Wang R and Soderhall K (2000). A lipopolysaccharide- and beta-1,3-glucan-binding protein from hemocytes of the freshwater crayfish Pacifastacus leniusculus. Purification, characterization, and cDNA cloning. J. Biol. Chem. 275: 1337-1343.

Li HJ, Liu WD, Gao XG, Zhu D, et al. (2011). Identification of host-defense genes and development of microsatellite markers from ESTs of hard clam Meretrix meretrix. Mol. Biol. Rep. 38: 769-775.

Li HJ, Yang Q, Gao XG, Su H, et al. (2012). Identification and expression of a putative LPS-induced TNF-alpha factor from Asiatic hard clam Meretrix meretrix. Mol. Biol. Rep. 39: 865-871.

Lin YC, Vaseeharan B and Chen JC (2008). Identification and phylogenetic analysis on lipopolysaccharide and beta-1,3- 
glucan binding protein (LGBP) of kuruma shrimp Marsupenaeus japonicus. Dev. Comp. Immunol. 32: 1260-1269.

Liu F, Li F, Dong B, Wang X, et al. (2009). Molecular cloning and characterisation of a pattern recognition protein, lipopolysaccharide and beta-1,3-glucan binding protein (LGBP) from Chinese shrimp Fenneropenaeus chinensis. Mol. Biol. Rep. 36: 471-477.

Livak KJ and Schmittgen TD (2001). Analysis of relative gene expression data using real-time quantitative PCR and the $2^{-\Delta \Delta C \mathrm{~T}}$ method. Methods 25: 402-408.

Medzhitov R and Janeway CA Jr (2002). Decoding the patterns of self and nonself by the innate immune system. Science 296: 298-300.

Nikapitiya C, De Zoysa M and Lee J (2008). Molecular characterization and gene expression analysis of a pattern recognition protein from disk abalone, Haliotis discus discus. Fish Shellfish Immunol. 25: 638-647.

Ochiai M and Ashida M (2000). A pattern-recognition protein for beta-1,3-glucan. The binding domain and the cDNA cloning of beta-1,3-glucan recognition protein from the silkworm, Bombyx mori. J. Biol. Chem. 275: 4995-5002.

Pipe RK (1990). Hydrolytic enzymes associated with the granular haemocytes of the marine mussel Mytilus edulis. Histochem. J. 22: 595-603.

Su JG, Song LS, Xu W, Wu LT, et al. (2004). cDNA cloning and mRNA expression of the lipopolysaccharide- and beta1,3-glucan-binding protein gene from scallop Chlamys farreri. Aquaculture 239: 69-80.

Tamura K, Dudley J, Nei M and Kumar S (2007). MEGA4: Molecular Evolutionary Genetics Analysis (MEGA) software version 4.0. Mol. Biol. Evol. 24: 1596-1599.

Wang Y, Hu M, Chiang MW, Shin PK, et al. (2012). Characterization of subpopulations and immune-related parameters of hemocytes in the green-lipped mussel Perna viridis. Fish Shellfish Immunol. 32: 381-390.

Wang YC, Chang PS and Chen HY (2007). Tissue expressions of nine genes important to immune defence of the Pacific white shrimp Litopenaeus vannamei. Fish Shellfish Immunol. 23: 1161-1177.

Yang Q, Yang Z and Li H (2011). Molecular characterization and expression analysis of an inhibitor of NF-kappaB (IkappaB) from Asiatic hard clam Meretrix meretrix. Fish Shellfish Immunol. 31: 485-490.

Yoshida H, Kinoshita K and Ashida M (1996). Purification of a peptidoglycan recognition protein from hemolymph of the silkworm, Bombyx mori. J. Biol. Chem. 271: 13854-13860.

Yue X, Liu B, Xiang J and Jia J (2010). Identification and characterization of the pathogenic effect of a Vibrio parahaemolyticus-related bacterium isolated from clam Meretrix meretrix with mass mortality. J. Invertebr. Pathol. 103: 109-115.

Yue X, Liu B and Xue Q (2011a). An i-type lysozyme from the Asiatic hard clam Meretrix meretrix potentially functioning in host immunity. Fish Shellfish Immunol. 30: 550-558.

Yue X, Liu B, Sun L and Tang B (2011b). Cloning and characterization of a hsp70 gene from Asiatic hard clam Meretrix meretrix which is involved in the immune response against bacterial infection. Fish Shellfish Immunol. 30: 791-799.

Zhang D, Ma J, Jiang J, Qiu L, et al. (2010). Molecular characterization and expression analysis of lipopolysaccharide and beta-1,3-glucan-binding protein (LGBP) from pearl oyster Pinctada fucata. Mol. Biol. Rep. 37: 3335-3343. 